\title{
ЭКОНОМИЧЕСКИЙ МЕХАНИЗМ ПРИВЛЕЧЕНИЯ ИНВЕСТИЦИЙ В ПРОМЫШЛЕННОСТЬ
}

\author{
(C) 2020 Ганеев А. М. \\ научный сотрудник \\ Институт экономики РАН, Россия, Москва \\ E-mail: Azat.g@rambler.ru \\ SPIN-код: 9372-3330, AuthorID: 703748
}

В данной статье рассматриваются специальный инвестиционный контракт и соглашение о защите и поощрении капиталовложений как инструменты привлечения инвестиций в промышленность. Автор анализирует механизм привлечения инвестиций с применением специального инвестиционного контракта и соглашения о защите и поощрении капиталовложений с целью роста экономики и повышения конкурентоспособности промышленности России.

Ключевые слова: инвестиции, привлечение инвестиций, промышленность

В феврале 2020 года президент РФ В.В.Путин заявил, что «..задача экономической повестки запуск нового инвестиционного цикла, выход на ежегодные темпы прироста инвестиций не ниже пяти, а лучше пяти-семи процентов, чтобы уже в следующем году обеспечить темпы экономического роста выше мировых» [5].

Однако, согласно Росстату, за январь - сентябрь 2020 года инвестиции в основной капитал в РФ в годовом выражении понизились на $4,1 \%$ [6]. В условиях санкций и пандемии произошло значительное сокращение инвестиций в российские экономические проекты. В связи с этим поиск новых источников инвестиций как внутренних, так и внешних, становится важнейшей задачей для развития экономики страны.

В текущей обстановке одним из основных инструментов привлечения инвестиций, на наш взгляд, могут стать формы и механизмы государственно-частного партнерства.

А.Г.Зельднер определяет государственночастное партнерство как «систему организационно-экономических отношений, предполагающую закрепление на контрактной основе прав и ответственности органов власти и бизнеса за совместное использование инвестиционных и других ресурсов, паритетное разделение рисков и прибыли, достижение конечных результатов при реализации крупных инфраструктурных проектов, а также перераспределение правомочий собственности и социализацию общественных отношений.» [1]

Федеральным законом от 31.12.2014 № 488Ф3 «О промышленной политике в Российской
Федерации» была создана новая форма ГЧП специальный инвестиционный контракт (СПИК). В рамках данного контракта инвестор берет обязательства по созданию или модернизации и (или) освоению производства промышленной продукции на территории России, а Российская Федерация или субъект РФ обязуется предоставить предусмотренные по закону меры стимулирования (льготы и преференции).

По данным министерства промышленности и торговли с момента создания механизма СПИК за первые три года с инвесторами было подписано 40 контрактов общей стоимостью около триллиона рублей [7].

В августе 2019 года были приняты значительные изменения в регулирующем СПИК законодательстве: был увеличен срок заключения СПИК, инвестиционный проект отбирается на конкурсной основе, отменен инвестиционный порог, необходимость внедрения или разработки и последующего внедрения современной технологии в производство промышленной продукции(технология должна быть включена в перечень современных технологий, который устанавливается постановлением правительства). Изменения распространяются на новые проекты, не получившие одобрение на дату вступления нововведений в силу.

Безусловно, важнейшим изменением является новый обязательный критерий для участия в соглашении - наличие современной технологии в разработке или в производственном процессе. Производство промышленной продукции с применением современных техноло- 
гий один из важнейших факторов повышения уровня конкурентоспособности отечественной промышленности. Однако для производств, не применяющих инновационные технологии, это означает отсутствие льгот и преференций и, таким образом, падение объема привлеченных капиталовложений в связи со снижением инвестиционной привлекательности.

В рамках контракта инвестор получает право на: льготы по налогам и закрепление налогового режима, статус и привилегии российского продукта, в определенных случаях возможны субсидии.

Одним из первых проектов, заключенных после изменений в законодательстве, стал специальный инвестиционный контракт (СПИК) с китайским автопроизводителем Haval, предполагающий локализацию производства автомобилей в России. Сумма контракта $-42,4$ млрд. рублей.

Еще одним из перспективных механизмов государственно-частного партнерства стало Сoглашение о защите и поощрении капиталовложений (СЗПК), созданное законом № 69 ФЗ от 1 апреля 2020 года. Согласно закону инвестору гарантируется неизменность налогового режима, а также возможность получить субсидию на строительство инфраструктуры в объеме уплаченных налогов. Длительность сохранения условий по налогам зависит от объема инвестиций в проект - от 6 до 20 лет. Минимальный инвестиционный порог составил - 250 миллионов рублей.

СЗПК позволяет привлекать как внутренние ресурсы, так и иностранные инвестиции, одновременно гарантируя стабильность налогообложения для бизнеса и инвесторов.

В 2020 году готовы к заключению 8 проектов по СЗПК общим объемом инвестиций более 129 млрд. рублей, к 2024 г. - планируется около 1000 соглашений на сумму 14,1 трлн. руб. [8]

Так отобран для заключения проект с «ФосАгро» по созданию комплекса, производящего фосфорсодержащие удобрения, в Волхове Ленинградской области. Предполагаемый объем инвестиций -28 млрд. рублей. В рамках проекта компания планирует увеличить на Волховском химическом комплексе выпуск продукции в 4 раза и создать свыше 200 рабочих мест для высококвалифицированного персонала.

Также близки к заключению еще несколько проектов, в частности - открытие группой компаний «Р-Фарм» высокотехнологичного фармацевтического предприятия в Москве, инвестиции должны составить 8,6 млрд. рублей.

Одним из главных преимуществ данного механизма является снижение рисков именно в долгосрочной перспективе. Для осуществления капиталоемких инновационных проектов важна возможность планирования на длительный период и СЗПК предоставляет необходимую стабильность для их успешной реализации.

В связи с тем, что механизм СПИК сменил направленность на привлечение инвестиций в производства с применением высоких технологий, СЗПК необходим для привлечения инвестиций в промышленное производство в целом.

В условиях тяжелой внешнеполитической и внешнеэкономической обстановки СПИК и СЗПК дают возможность эффективно решить острую проблему дефицита инвестиций, позволяют привлечь современные технологии в отечественное промышленное производство, создать рабочие места, в том числе высококвалифицированные, и способствуют повышению конкурентоспособности промышленности и качественному развитию экономики России.

\section{Библиографический список}

1. Зельднер, А.Г. ГЧП - мейнстрим современной российской экономики. // Мир перемен. - 2014. - № 1.- С. $140-143$.

2. Зельднер А. Г. Специальный инвестиционный контракт в управлении привлечением частных инвестиций в модернизацию промышленности // Экономические науки. 2019. № 9. С. 82-86.

3. Доржиева B.B., Ильина С.А. Институты развития как инструменты поддержки малого и среднего предпринимательства // Вестник Института экономики Российской академии наук. 2020. № 4. С. 58-72.

4. Скрыль Т.В., Осипов В. С. Устойчивое Экономическое развитие: аспекты промышленной политики // Экономика и предпринимательство. 2016. № 1-2 (66). С. 719-726.

5. http://www.kremlin.ru/events/president/news/62767

6. https://tass.ru/ekonomika/10060523?utm_source=yxnews \&utm_medium=desktop

7. https://rg.ru/2020/02/11/kakie-dopolneniia-vneseny-v-specialnyj-investicionnyj-kontrakt.html

8. https://www.vedomosti.ru/economics/articles/2020/10/08/842635-pravitelstvo-zapuskaet 